\title{
Preface - Special Issue Dedicated to Professor Shinji Murai
}

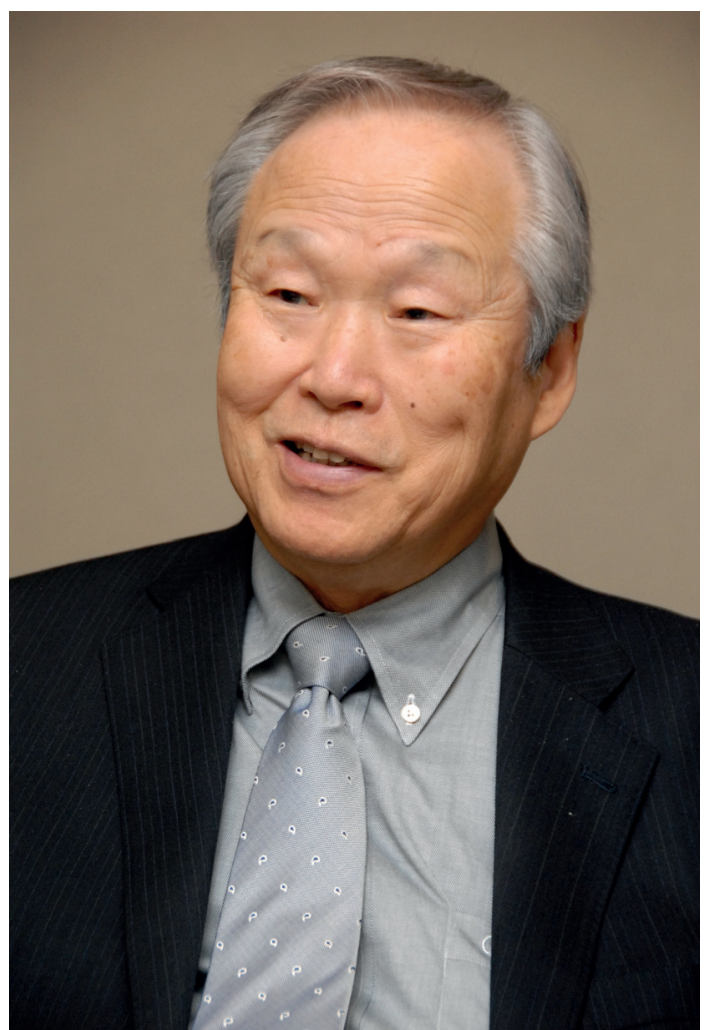

It is both a pleasure and an honor for us to contribute to this Special Issue of SYNTHESIS on 'Bond Activation - in Honor of Prof. Shinji Murai'.

Prof. Shinji Murai was born in Osaka in 1938 and received his B.Sc. in 1961 and his Ph.D. in 1966 from Osaka University under the guidance of Prof. Shigeru Tsutsumi. He was appointed as an Assistant Professor at Osaka University in 1966, an Associate Professor in 1973, and a Full Professor in 1989. He undertook postdoctoral studies between 1966 and 1967 with Prof. Robert West at the University of Wisconsin-Madison. He served as Dean of the Faculty of Engineering, Osaka University from 1999 to 2001 and, in 2002, he became a Professor Emeritus at Osaka University.

Prof. Murai's research was directed toward the development of novel types of organic transformations, especially catalytic reactions. One of his notable contributions during his early career was the development of a series of remarkable reactions using hydrosilanes and carbon monoxide. The reactions initially used a $\mathrm{Co}_{2}(\mathrm{CO})_{8}$ catalyst (Angew.
Chem., Int. Ed. Engl. 1977, 16, 174); however, these reactions were subsequently expanded to incorporate various transition-metal catalysts as well as a variety of substrates. I (N.C.) was involved in this project when I joined Prof. Murai's group as an undergraduate student. Our first paper was a study of $\mathrm{Co}_{2}(\mathrm{CO})_{8}$-catalyzed reactions of esters with hydrosilanes and carbon monoxide (J. Am. Chem. Soc. 1983, $105,1370)$. This research had a huge impact on my life. I would not have pursued an academic career had I not been involved in this project. Since then, we managed to publish more than 15 manuscripts on this subject. The chemistry associated with this reaction has been summarized in an impressive account (Synlett 1996, 414), with the most recent paper having been published this year (Bull. Chem. Soc. Jpn. 2021, 94, 81). Many of these reactions involve the cleavage of $\mathrm{C}-\mathrm{O}$ bonds. We now describe this type of process as $\mathrm{C}-\mathrm{O}$ bond activation. Prof. Murai is a man of keen perception.

Considering his great interest in novel transition-metalcatalyzed reactions, the discovery of the Murai reaction was not an unexpected event (Nature 1993, 366, 529). In this reaction, a ruthenium complex selectively activates the ortho$\mathrm{C}-\mathrm{H}$ bond of an aromatic ketone, which had previously been considered to be difficult and even impossible, and then catalyzes the addition of the $\mathrm{C}-\mathrm{H}$ bond across the double bond of an alkene. The Murai reaction is now associated with impressive product yields, selectivity, and atom-economy, and is epoch-making in that it involves a catalytic, directed bond activation. Importantly, Prof. Murai clearly showed that the $\mathrm{C}-\mathrm{H}$ bond activation, i.e., oxidative addition, is not as difficult to achieve as was originally expected (Bull. Chem. Soc. Jpn. 1995, 68, 62), which is a guiding principle in exploring the catalytic activation of inert bonds. Prof. Murai has undoubtedly contributed to a quantum leap in the development of the chemistry of inert bond activation (Acc. Chem. Res. 2002, 35, 826). As an additional note, he edited the first book dealing with the chemistry of the transition-metal-mediated activation of inert bonds (Activation of Unreactive Bonds and Organic Synthesis, SpringerVerlag, 1999), which is now considered to be a 'bible' for those involved in research on bond activation. His work on transition-metal catalysts has clearly changed the landscape of organic synthesis.

Some of Prof. Murai's recognitions include the following: The Chemical Society of Japan Award in 1997, the Special Award in Synthetic Organic Chemistry, Japan, in 2004, the Fujihara Award in 2006, the Japan Academy Prize in 2010, the Order of the Sacred Treasure in 2013, the Asahi Prize in 2016, and the Person of Cultural Merit in 2017. 
Prof. Murai has always supported our society and has continually provided encouragement to organic chemists in Japan. He served as the Representative Director of Grant-inAid for Scientific Research on Priority Areas (Innovative Synthetic Reactions, 1997-2001), MEXT, and as the Research Supervisor of PRESTO (Synthesis and Control, 20012006), a program of the Japan Science and Technology Agency (JST) (a funding subsidiary of the Japanese government), to support promising young organic chemists. After retiring from Osaka University in 2002, he moved to the JST as an Executive Fellow. He was elected President of the Society of Synthetic Organic Chemistry, Japan, in 2001 and served as President of the Chemical Society of Japan in 2005. Also in 2005, he was appointed as a Director, Vice President, and then a Specially Appointed Professor at the Nara Institute of Science and Technology. Since 2013, he has served as a Director for the Iwatani Cooperation R\&D Center, and since 2016 as an Outside Director.
Most importantly, Prof. Murai has nurtured his students and colleagues by providing them with passionate supervision and he continues to captivate the attention of chemists worldwide in the field of bond activation. On behalf of all the contributors to this Special Issue of SYNTHESIS, we wish to extend our best wishes to Prof. Murai in his future endeavors and for his health.

Naoto Chatani, Guest Editor, SYNTHESIS

Department of Applied Chemistry, Faculty of Engineering, Osaka University

Hideki Yorimitsu, Associate Editor, SYNTHESIS

Department of Chemistry, Graduate School of Science, Kyoto University 